\title{
Justicia internacional e inmigración, necesidad de constelar diferentes principios normativos*
}

\author{
International Justice and Immigration, \\ the Need to Constellate Different Normative Principles
}

ASUNCIÓN HERRERA GUEVARA**

\begin{abstract}
Resumen: Este artículo analiza la necesidad de repensar el concepto de justicia internacional. $\mathrm{Si}$ queremos una teoría de la justicia capaz de dar respuesta a problemas como el de la inmigración, es preciso marcar el comienzo de una nueva justicia global. Analizaré la obra El derecho de gentes de Rawls y la propuesta sobre inmigración de David Miller. En ambos casos, intentaré subrayar las carencias apoyándome en el trabajo de Nancy Fraser. El artículo concluye presentando una propuesta, en el campo de la justicia internacional, de constelación de principios y asumiendo el nuevo enmarque fraseriano.

Palabras clave: justicia internacional, inmigración, constelación de principios, Nancy Fraser.
\end{abstract}

\begin{abstract}
This paper argues the need to rethink the concept of International Justice. If we want a theory of justice that resolves the topics of Immigration, then is necessary to usher in a new global justice. I will analize the work of Rawls The Law of Peoples and the proposed about Immigration of David Miller. I will show the lacks of both works and I will lean on the work of Nancy Fraser. The paper concludes that is necessary to propose in International Justice a constellation of principles and to assume the new framing of Fraser.
\end{abstract}

Keywords: International Justice, Immigration, Constellation of principles, Nancy Fraser.

\section{Introducción}

Nadie dudaría de la heterogeneidad y de la pluralidad convulsa de avatares que hemos vivido a lo largo de todo el devenir del siglo XX. Pluralidad de acontecimientos de diferente calado: unos emancipadores y otros muchos sangrientos, que hicieron replantearse las

Recibido: 23/12/2015. Aceptado: 24/03/2016

* La presente contribución ha sido realizada en el marco del proyecto de investigación Civic Constellation II: Debating Democracy and Rights (FFI2014-52703-P), financiado por el Programa Estatal de Investigación Científica y Técnica de Excelencia.

** Profesora Titular del Departamento de Filosofía de la Universidad de Oviedo. Correo-e: aherrera@uniovi.es Líneas de investigación en las que trabaja: modernidad, globalización, justicia internacional, Ilustración, dilemas bioéticos del presente. Entre sus últimos trabajos caben destacar el artículo «Constelar la ética cognitiva con el pensamiento existencial: la necesaria revitalización de las emociones» en Pensamiento, Vol. 69, 2013, pp. 103-114 y el libro Ilustrados o bárbaros, Madrid, Plaza y Valdés, 2014. 
estructuras morales y políticas de las sociedades occidentales. Sin lugar a dudas, una de las consecuencias de los continuos conflictos bélicos vividos en una Europa ilustrada fue la reconstrucción de una teoría de la justicia. Ver cómo se reconstruyó el concepto de justicia, tanto en el ámbito doméstico como en el internacional, será uno de los objetivos del artículo; analizar la problemática internacional con el fin de proponer la necesidad de constelar, dentro de este espacio global, varios principios, será el otro punto central de discusión a lo largo de las siguientes páginas.

La Europa que surge de las cenizas del año 45 tendrá que rehacer tanto sus bombardeadas ciudades como su resquebrajado imaginario político. La matanza de cinco millones de judíos en pleno siglo XX ocurrió en la Europa del Imperio de la ley. Los pensadores que vivieron ese acontecimiento reflexionaron sobre el alfa que había conducido a un omega tan maléfico y cruento. Obras como las de Adorno y Horkheimer Dialéctica de la Ilustración, o de Arendt Los orígenes del totalitarismo, reflexionaron sobre el origen de nuestra culpa, sobre nuestra herida condición humana o sobre la banalidad del mal ${ }^{1}$. Sus discursos, criticados por algunos intérpretes por realizar una crítica totalizadora de la razón, buscaron causas y explicaciones de lo inexplicable, del mal radical encarnado en el espíritu europeo del siglo XX. Adorno fue más lejos en sus pretensiones e intentó rastrear un atisbo de redención, una esperanza, con el fin tal vez de poder seguir haciendo filosofía ${ }^{2}$.

Desbaratados la mayor parte de los planteamientos políticos anteriores al conflicto bélico, surge la necesidad de abordar las cuestiones morales, las cuestiones de justicia, sin volver a cometer el error de instrumentalizar a millones de seres humanos, al menos así es como lo plantearán los pensadores morales y políticos occidentales ${ }^{3}$. El este europeo, sin hacer la misma lectura, comenzó otra maquinaria de destrucción llamada Gulag.

Evitar cualquier estructura política y social capaz de «triturar carne ${ }^{4}$ obligó a una revisión de las hasta ahora teorías de la justicia. La revisión se realizará en dos niveles, tanto a nivel doméstico, es decir dentro de las fronteras de los Estados territoriales, como a nivel internacional.

El estado nación no se había preocupado en demasía por las condiciones socioeconómicas de sus ciudadanos. Ni la justicia social ni la justicia de género -por poner dos ejemplos de justicia que van más allá de la mera ligazón de lo justo con la libertad como no interferencia- habían copado las preocupaciones políticas.

1 Véase Adorno, T. W. y Horkheimer, M., Dialéctica de la Ilustración, Madrid, Trotta, 1994; véase también Arendt, H., Los orígenes del totalitarismo, Madrid, Taurus, 1998.

2 Véase Adorno, T. W., Minima moralia, Madrid, Taurus, 1987. El último parágrafo de esta obra muestra claramente la necesidad adorniana de encontrar una posible redención, evidentemente, una salvación sin Mesías, un Absoluto velado en negro. De igual modo en «Después de Auschwitz» en Dialéctica negativa reflexiona sobre la posibilidad de seguir haciendo filosofía tras los trágicos acontecimientos que acaba de vivir Europa. Véase también Adorno, T. W., Dialéctica negativa, Madrid, Taurus, 5 a reimp., 1992.

3 Utilizaré la terminología empleada por autores alemanes como Habermas de tal modo que las cuestiones morales son cuestiones de justicia mientras que las cuestiones éticas abarcan el campo de la vida buena. Para una detallada clasificación véase Habermas, J., «Una consideración genealógica acerca del contenido cognitivo de la moral», en La inclusión del otro, Barcelona, Paidós, 1999, pp. 29-78.

4 Esta expresión era utilizada por los propios prisioneros de los campos de concentración al referirse al Gulag. Véase al respecto el libro de Applebaum, A., Gulag: Historia de los campos de concentración soviéticos, Barcelona, Penguin Random House, 2012. 
Es cierto que somos herederos tanto de la tradición liberal como de la republicana y, por lo tanto, podríamos pensar que nunca nos hemos sentido cómodos con una aceptación, sin más, de los derechos subjetivos modernos. Nuestro espíritu republicano se ha rebelado contra una mera libertad formal entendida como no interferencia y ha exigido más, a saber, el disfrute material de esa libertad, que sólo puede venir de la mano de la no dominación. Siendo dominados no podremos disfrutar de nuestros derechos. Por lo tanto, la no interferencia libertaria se matiza con una no interferencia arbitraria que pueda garantizar el disfrute de los derechos 5 .

En terminología de Habermas, autonomía privada y autonomía pública son la otra cara del liberalismo y el republicanismo, cuando dilucidan sobre la legitimidad del poder político. La primera hace recaer el peso de la legitimidad en el Imperio de la ley, la segunda en el demos, en la soberanía popular. Para el pensador alemán, no sólo se necesitan mutuamente, sino que son cooriginarias a la hora de pensar en la constitución de los estados modernos. La primera nos garantizaría los derechos subjetivos modernos, la segunda nos impele a ser copartícipes en la construcción de esos mismos derechos. Si nos quedamos al margen de su elaboración, surgirán disfunciones propias de un estado que intenta imponer a sus ciudadanos unas leyes emanadas no del demos, sino de un rey o filósofo rey.

Después de la Segunda Guerra Mundial es cuando surgió la verdadera necesidad de replantearse la cooriginariedad de nuestro origen político. Las cuatro primeras décadas del siglo XX nos enseñaron que un liberalismo, no sensible a la dominación y a la participación política, bien pudiera conducirnos a la instrumentalización de millones de seres humanos.

A partir de los años 50 el debate sobre igualitarismo social, capaz de evitar la dominación, y de garantizar la participación paritaria en la política de numerosas minorías, hasta ahora ninguneadas, entra en escena a fin de evitar los desmanes acaecidos en décadas anteriores.

En teoría de la justicia aparece la figura de John Rawls: su obra de 1971 revoluciona la teoría política ${ }^{6}$. El liberalismo igualitarista de Rawls permite la confluencia de la defensa de la libertad con el otro gran problema moral, la igualdad ${ }^{7}$. A partir de este momento, tratar las cuestiones morales sin plantearse una dimensión redistributiva se hace insostenible en el espacio de los estados nacionales.

Ahora bien, el replanteamiento de la teoría de la justicia, como antes señalé, no se realiza sólo a nivel nacional, la esfera internacional también exigirá cambios.

5 Recojo las dos fuentes clásicas de nuestro pensamiento político, la tradición liberal iniciada en la época moderna por Locke y la republicana por Rousseau. No estoy teniendo en cuenta republicanismos premodernos. Ambas líneas de pensamiento mantuvieron diferencias en cuanto a la concepción de la libertad o al responder a la pregunta sobre dónde reside la legitimidad del poder. Libertad como no interferencia, definición liberal, o como no interferencia arbitraria, definición republicana, son dos concepciones divergentes y con consecuencias sociopolíticas dispares. Hacer recaer la legitimidad del poder en el Imperio de la Ley o en la soberanía popular también traerá modelos de hacer política diferentes. Véase Pettit, P., Republicanismo, Barcelona, Paidós, 1999, pp. 35-75.

6 Véase Rawls, J., Teoría de la justicia, México, FCE, 1979.

7 Recuérdese la formulación de sus dos principios de justicia: «Primero: Cada persona ha de tener un derecho igual al esquema más extenso de libertades básicas iguales que sea compatible con un esquema semejante de libertades para los demás. Segundo: Las desigualdades sociales y económicas habrán de ser conformadas de modo tal que a la vez que: a) se espere razonablemente que sean ventajosas para todos, b) se vinculen a empleos y cargos asequibles para todos» en Teoría de la justicia, op. cit., p. 82. 
Tras la Segunda Gran Guerra, los Juicios de Núremberg mostraron a la comunidad internacional la necesidad de replantearse la justicia a nivel global. En aquél momento tan sólo los tribunales alemanes podían juzgar a sus dirigentes. Las atrocidades del estado nazi permitieron una visión más global del crimen y, por primera vez, líderes nazis fueron juzgados y acusados como criminales de guerra por un Tribunal Internacional. Evidentemente, la justicia internacional cobra un peso del que carecía hasta el momento. Un organismo global exigirá la defensa de los derechos humanos. Es cierto que en Núremberg se hace una lectura minimalista de los derechos humanos, es decir: se está juzgando a líderes que han cometido crímenes contra la humanidad, se persigue un genocidio. El debate actual de la justicia internacional abarcaría la necesidad de ir más allá y plantearse la lectura maximalista de los derechos humanos. Esta actual revisión exigiría nuevas y reformadas instituciones globales capaces de perseguir a estados, gobiernos o instituciones no gubernamentales, que violasen derechos humanos no catalogados como crímenes contra la humanidad.

Lo que queda de manifiesto es que a raíz de los graves acontecimientos de las cuatro primeras décadas del siglo XX, la teoría de la justicia, tanto en el plano nacional como internacional, se repiensa y cambia.

En los siguientes apartados del presente artículo intentaré mostrar cómo ante determinados problemas que superan las fronteras, como por ejemplo la problemática de la inmigración, el planteamiento conceptual de una teoría de la justicia a nivel global ha de ser repensado de nuevo. Para llegar a la defensa de un nuevo planteamiento, explicaré en un primer apartado lo que supuso la obra de Rawls El derecho de gentes y las críticas a su planteamiento. Me detendré en las críticas llevadas a cabo por Nancy Fraser. En un segundo apartado examinaré el posicionamiento de un nacionalista liberal como David Miller ante el tema de la inmigración; las limitaciones de su planteamiento y la superación de estos problemas en Escalas de justicia de Fraser. A continuación, propondré la necesidad de constelar enfoques a la hora de responder al quién de la justicia internacional. Desde mi punto de vista será necesario constelar el principio de todos los sujetos de Fraser con algún otro principio de corte cosmopolita. En la búsqueda de este principio recontextualizaré la idea de sí mismo de un filósofo clásico, Kierkegaard, para apoyar una visión humanista de lo internacional, que podría aplicarse al caso de los inmigrantes. Por último, justificaré con tres argumentos la asunción de mi propuesta constelativa.

\section{Controversia suscitada alrededor de El derecho de gentes: planteamiento de un liberal igualitarista}

La Teoría de la justicia publicada por Rawls en los setenta señala una nueva concepción de la justicia en el ámbito doméstico, es decir, dentro de los estados territoriales. Más aún, elabora un concepto de lo razonable, en el marco de su teoría de la justicia, con fuerte sesgo sustantivo ${ }^{8}$. Las partes en la posición original adoptan un criterio público de

8 Una caracterización de lo razonable frente a lo racional en Rawls podría ser la siguiente: la racionalidad capacita a las personas para conocer con precisión sus propios intereses, percibir las consecuencias de una práctica y adherirse a un curso de acción después de decidirlo. La razonabilidad va unida a un deseo de imparcialidad, en el sentido de que expresa el reconocimiento de los reclamos de los demás como merecedores de igual consideración que los propios. 
justicia sustantiva y social; hasta tal punto esto es así, que toda teoría que no acepta esta idea de justicia será tachada de irrazonable. Rawls no se conforma, en el caso doméstico, con otorgar un mero valor epistémico a la justicia, que tan sólo exigiría un procedimiento razonable de justicia capaz de garantizar la legitimidad de los resultados. Por el contrario, construye un concepto sustantivo de lo razonable, y por ende una concepción sustantiva de la justicia, ejemplificada en sus dos principios, como garantía de la legitimidad.

Su obra del año 1999 El derecho de gentes no aborda de la misma manera la justicia dentro del marco internacional ${ }^{9}$. Podríamos dar diferentes razones por las que Rawls se aleja de una caracterización sustantiva de lo razonable en el espacio global. Me centraré en dos de sus argumentos. El primero tiene que ver con cómo entiende el «quién» y el «qué» de la justicia; el segundo, tendrá que ver con su concepción de la tolerancia liberal ${ }^{10}$.

Con respecto al «quién» de la justicia en el ámbito internacional, Rawls lo deja muy claro a lo largo de su obra. Se distancia de todo proyecto que pretenda una concepción política y moral de justicia cosmopolita liberal: él, a diferencia de los cosmopolitas, no opera con individuos sino con pueblos:

Estas observaciones ilustran el contraste entre el derecho de gentes y una perspectiva cosmopolita. La preocupación última de una perspectiva cosmopolita es el bienestar de los individuos y no la justicia de las sociedades [...] (La perspectiva cosmopolita) se preocupa por el bienestar de los individuos y por si el bienestar de la persona en peor condición en el ámbito global puede mejorar. Para el derecho de gentes lo importante es la justicia y la estabilidad, por las razones correctas, de las sociedades liberales y decentes que viven como miembros de una sociedad de los pueblos bien ordenados ${ }^{11}$.

Los individuos ya no serán la respuesta adecuada para el «quién» de la justicia, a diferencia del caso doméstico, entran en juego las colectividades que el filósofo liberal denomina «pueblos» ${ }^{12}$. Evidentemente, la modificación del «quién» va en correlación con el cambio en la respuesta al «qué». En los estados territoriales, una justicia centrada en el individuo tenía la obligación sustantiva de legitimarse a través de una sociedad bien ordenada con instituciones, que debían seguir una concepción sustantiva de justicia, y que garantizaban la redistribución de bienes y, por lo tanto, el bienestar de los individuos ${ }^{13}$.

9 Véase Rawls, J., El derecho de gentes, Barcelona, Paidós, 2001.

10 Intencionadamente utilizaré la terminología que emplea Nancy Fraser en Escalas de justicia. Con posterioridad me centraré en determinados argumentos de la filósofa estadounidense. La obra de Fraser ha sido central para «enmarcar» correctamente el tema de la justicia internacional y para hacer una lectura crítica de obras como la de Rawls. Espero dejar claro a lo largo de mi exposición tanto mi acercamiento a Fraser como mi intento de unir a su propuesta una dimensión que la pensadora norteamericana deja al margen. Véase, Fraser, N., Escalas de justicia, Barcelona, Herder, 2008.

11 Rawls, J., El derecho de gentes, op. cit., pp. 138-139. El paréntesis es mío.

12 Rawls utiliza el concepto «pueblo» frente a «Estado» con una clara intencionalidad: frente al Estado tradicional, con sus poderes de soberanía, los pueblos liberales y decentes limitan sus intereses básicos como lo exige lo razonable. Véase Rawls, J., Ibídem, pp. 37-40.

13 Rawls se distancia de proyectos cosmopolitas como los de Brian Barry (1989), Charles Beitz (1979) y Thomas Pogge (1990). 
El derecho internacional, en la visión rawlsiana, sigue siendo un derecho que media las relaciones entre colectividades. Muestra una ceguera total, siguiendo la terminología de Fraser, ante el nuevo marco que exigiría el fenómeno de la globalización. Un quién colectivo llamado pueblo será el sujeto de la justicia internacional, de tal modo, que no nos hemos de centrar en una justicia sustantiva que permita responder a un qué redistributivo, sino en una justicia epistémica que de respuesta a un qué, centrado en la estabilidad entre los diferentes pueblos liberales y decentes. Más aún, serán los pueblos situados en un mismo nivel los que podrán adoptar en una posición original los ocho principios del derecho de gentes ${ }^{14}$. Las partes, a nivel doméstico, adoptan, en la posición original, un criterio público de justicia social; en el caso internacional, las partes son requeridas para que aprueben directamente unas reglas internacionales (los ocho principios). Lo razonable en el derecho de gentes no requiere que las partes se adhieran a una concepción sustantiva de la justicia, sólo exige el criterio de reciprocidad: «Así el criterio de reciprocidad se aplica al derecho de gentes en la misma forma que los principios de justicia para un régimen constitucional» ${ }^{15}$.

El segundo argumento al que se adhiere Rawls para rechazar una concepción sustantiva de lo razonable, en el espacio internacional, y, por ende, un concepto sustantivo de justicia, tiene que ver con su caracterización de la tolerancia liberal. El miedo de Rawls, como dice Allen Buchanan, a la acusación de promover unos derechos humanos parroquianos, le lleva a rechazar una concepción sustantiva de justicia y a reducir drásticamente, como consecuencia, la lista de los derechos ${ }^{16}$. Rawls distinguirá claramente entre los derechos que pueden disfrutar los ciudadanos dentro de su estado territorial, y los derechos más limitados del espacio internacional.

Desde mi punto de vista, la ceguera de Rawls, a la hora de abordar el tema de la justicia internacional, tiene que ver con otorgar meramente un valor epistémico y no sustantivo a lo razonable. La sustantividad de lo razonable en el caso doméstico -unido a una concepción sustantiva de justicia- permitía a la teoría de la justicia, por un lado, tener en cuenta las «cargas de la prueba» de los individuos - no todos parten de una situación igual- y por otro, posibilitaba el percatarse de que la neutralidad de lo razonable, frente a las formas de vida, no implicaba neutralidad de las consecuencias que las normas y disposiciones ejercen sobre los diferentes individuos. En el ámbito internacional estas dos consideraciones desaparecen. En primer lugar, los pueblos son requeridos, para que aprueben unas reglas internacionales, sin tener en cuenta que algunos parten con desventaja: tienen cargas que

14 Los ocho principios son los siguientes: 1. Los pueblos son libres e independientes, y su libertad e independencia son respetadas por otros pueblos; 2. Los pueblos deben cumplir los tratados y los convenios; 3 . Los pueblos son iguales y deben ser partes en los acuerdos que los vincula; 4. Los pueblos tienen un deber de no intervención; 5. Los pueblos tienen el derecho de autodefensa pero no el derecho de declarar la guerra por razones distintas a la autodefensa; 6. Los pueblos deben respetar los derechos humanos; 7. Los pueblos deben observar ciertas limitaciones específicas en la conducción de la guerra; 8. Los pueblos tienen el deber de asistir a otros pueblos que viven bajo condiciones desfavorables que les impiden tener un régimen político y social justo o decente (Rawls, J., El derecho de gentes, op. cit., p. 50).

15 Rawls, J., Ibídem, p. 48.

16 Véase Buchanan, A., «Taking the Human out of Human Rights», en: R. Martin, y D. A. Reidy, (eds.): Rawls's Law of Peoples. A realistic utopia?, Blackwell Publishing, 2006, p. 150. 
Rawls no parece apreciar ${ }^{17}$. En segundo lugar, el derecho de gentes se mostraría insensible a las consecuencias que las reglas ejercen sobre diversos pueblos con cargas tan diferentes.

Una de las críticas más sólidas, al planteamiento nacionalista liberal igualitarista de Rawls, será planteada por Fraser. Relaciona la ceguera rawlsiana con el problema del enmarque: ante un fenómeno como la globalización cabe replantearse el quién, el qué y el cómo de la justicia ${ }^{18}$. Fraser consigue dar una respuesta compacta a estos nuevos desafíos rompiendo con el caduco marco westfaliano. Fracturado este marco y en una situación, como la define la autora, de justicia anormal el quién ya no puede ser el mero ciudadano de un estado territorial, el qué de la justicia se amplia a una triple dimensión, a saber, a la redistribución y al reconocimiento se une la dimensión política de la representación. Y, por último, esta nueva concepción conduce a un nuevo cómo, es decir, cómo implementar institucionalmente ese quién y qué de la justicia internacional.

\section{El quién de la justicia internacional aplicado a un caso: la inmigración. Plantea- miento de un nacionalista liberal}

La respuesta de Fraser a esta cuestión supera muchas de las limitaciones de los planteamientos de cosmopolitas, internacionalistas y nacionalistas liberales. Basta con detenerse en alguna de estas propuestas, para ver sus importantes conflictos y contradicciones, cuando tratan cuestiones de justicia relacionadas con la inmigración o los refugiados. Este es el caso del nacionalista liberal David Miller. En su trabajo «Immigration: The Case for Limits» analiza tres argumentos a favor de la apertura de fronteras: el primero se centra en el derecho a la libertad de movimiento, el segundo explica que el derecho de salida conllevaría necesariamente un derecho de entrada y, por último, toma la inmigración como ejemplo de justicia internacional distributiva ${ }^{19}$. Tras analizarlos llega a la paradójica conclusión de que la obligación de acoger depende de si encuentro a alguien que quiera acoger. De igual modo que el derecho a casarse con alguien depende de si encuentro a alguien dispuesto a casarse. Mala analogía para quien pretende dirimir un tema de justicia. Un nacionalista liberal como él está admitiendo que se nos puede otorgar un derecho, el derecho de entrada, pero no se nos tiene porqué garantizar la realización material de ese derecho. Desde posiciones no liberales sí existe una preocupación por la libertad real y no meramente por una libertad formal. O lo que es lo mismo, nos preocuparíamos no meramente por la lista de derechos, sino por las condiciones que permiten la realización de esos mismos derechos. Además, Miller reforzará su blindada posición haciendo un guiño a dos de los argumentos más esgrimidos contra la apertura de fronteras: la preservación de la cultura autóctona y el control de población para garantizar la supervivencia ecológica y económica de las sociedades.

17 La única forma con la que intentaría paliar esta situación de desventaja parece ser con el principio ocho, es decir, con el deber de asistencia.

18 Aún siendo unos escépticos de la globalización, lo que nadie puede negar es la proliferación de acontecimientos sociales, políticos y económicos a escala global. Es inevitable la interpretación de problemas de género, de crisis económica o medioambiental más allá de los estados territoriales. Ni que decir tiene, el replanteamiento transnacional de un problema político como el de los inmigrantes o refugiados.

19 Miller, D., «Immigration: The Case for Limits», en: A. I. Cohen and C. H. Wellman (eds.): Contemporary Debates in Applied Ethics, Oxford, Blackwell Publishing, 2005, pp. 193-206. 
El trabajo de Miller es un buen ejemplo de respuesta y debate incapaz de saltar el marco westfaliano. Desde su posicionamiento se está cuestionando el verdadero alcance moral y político del tema de los inmigrantes y refugiados. Por un lado, los argumentos que analiza Miller y su propuesta siguen sin dejar claro si el quién de la justicia internacional abarca a una nueva «ciudadanía global». Al colocar en un mismo plano, pongamos por caso, el derecho de salida con el derecho a proteger la cultura autóctona de un posible país de acogida, evidentemente, convierte en un mero conflicto político lo que es un grave conflicto no sólo político sino moral. Por otro lado, duda sobre la necesidad de replantear el problema desde una concepción de justicia internacional distributiva. Estaría poniendo entre paréntesis, en el caso internacional, una dimensión central como respuesta al qué de la justicia: la dimensión redistributiva. Aún reconociendo el deber moral que tienen los países de intervenir en los casos en que no se respeten los derechos humanos, en los países de origen, acaba suscitando dudas a la apertura de fronteras por la posible fuga de talentos (personas con educación superior: médicos, ingenieros, etc.) de los países menos desarrollados a los más desarrollados. Resolver un problema de justicia internacional redistributiva con un mero cálculo de utilidades, colocando en un mismo plano el futuro de un país fallido con el futuro moral y político de un sujeto, que pretende escapar de unas condiciones nacionales y territoriales que le abocan a una vida fallida, vuelve a ser un ejercicio nacionalista liberal para blindar las fronteras.

Planteamientos como el de Miller seguirían encuadrando a la justicia internacional en un marco westfaliano, donde los estados nacionales, los ciudadanos nacionales y las estructuras políticas territoriales, serían los actores principales en el debate político sobre la apertura o blindaje de fronteras. Siguiendo con el planteamiento westfaliano, Miller reconoce la existencia de una obligación moral de todos los seres humanos con quienes huyen de sus estados, ante la violación de los derechos humanos pero, al mismo tiempo, separa esta obligación del debate político y pone demasiadas trabas a la hora de enmarcarla dentro de las obligaciones políticas a las que deben atenerse los ciudadanos. Como seres humanos tenemos la obligación de ayudar, premisa inexcusable, como ciudadanos el debate está abierto. Parecería como si, en este discurso que mantienen muchos liberales, la beneficencia fuese la primera virtud del humano pero no que esta misma ayuda sea una cuestión de justicia política.

Como la propia Fraser acaba reconociendo en su crítica a los dogmas del igualitarismo, aún a riesgo de que se nos acuse de moralizar la política, en un nuevo marco poswestfaliano deberíamos proponer un continuo entre moral y política. Tal continuo permitiría el tratamiento de los problemas transnacionales de justicia como problemas políticos, y por lo tanto, como obligaciones a las que deben atenerse los ciudadanos, y no como meros problemas morales. Si aceptamos este continuo, es necesario repensar, en el tratamiento de la justicia internacional, instituciones políticas que superen las barreras nacionales. Punto del que se alejan planteamientos como el de Miller.

La propuesta de Fraser perfila un nuevo principio capaz de responder al quién de la justicia en el nuevo marco poswestfaliano. Lo denomina el principio de todos los sujetos y lo define de la siguiente manera: «Una cuestión está justamente enmarcada si y sólo si todos y cada uno de los sometidos a la(s) estructura(s) de gobernación que regula(n) las áreas relevantes de la interacción social reciben igual consideración».

Con este principio, Fraser responde a los nuevos retos de la justicia internacional. Su propuesta me parece acertada y necesaria en el contexto de las nuevas relaciones transnacionales 
y globales. Quisiera subrayar en este punto la necesidad de constelar su enfoque con elementos presentes en el principio del humanismo o cosmopolitismo. Explicaré, más adelante, tres razones para apoyar mi propuesta. La primera tiene que ver con la continuidad entre cuestiones de justicia y cuestiones éticas; la segunda, con implementar la carga motivacional del principio fraseriano; y la tercera, con la respuesta al qué de la justicia internacional (realmente si queremos que la respuesta al qué sea tridimensional y abarque también la redistribución será preciso fijarse en el sujeto de carne y hueso y en sus necesidades y vulnerabilidad).

\section{Constelación de enfoques: el principio del humanismo yuxtapuesto al principio de todos los sujetos}

En los apartados anteriores he mostrado la insuficiencia de dos planteamientos clásicos de justicia internacional, uno desde el posicionamiento de un liberal igualitarista y otro desde un nacionalista liberal, a la hora de abordar cuestiones centrales en el espacio de una sociedad globalizada. La propuesta de Fraser, en Escalas de justicia, supera muchas de las limitaciones anteriores al situar su planteamiento en un marco necesariamente poswestfaliano. Su enfoque la lleva a formular el principio de todos los sujetos al que me he referido en el apartado previo ${ }^{20}$.

Frente a los enfoques anteriores, con este principio se garantizaría que aún sin ser miembro de una estructura de gobernación, los sujetos estarían amparados ante las injusticias enmarcadas en un nivel transnacional ${ }^{21}$. Basta con estar sujeto a cualquier estructura de gobernación, que regule las áreas relevantes de la interacción social, para que ese sujeto reciba igual consideración. Y, es evidente, como reconoce la autora, que vivimos en un mundo globalizado donde podemos estar sujetos al poder coercitivo de una gobernabilidad no estatal. Por ello, siguiendo con el ejemplo de la inmigración, los inmigrantes sí están sujetos a estructuras de gobernación transnacionales que regulan sus interacciones sociales. Por ejemplo, una persona puede no estar acreditada ante una estructura de la UE, pero las decisiones de esta afectan a las condiciones de vida de tal persona. Por lo tanto, esta estructura estaría obligada a darle representación ${ }^{22}$.

Como he señalado al final de la sección anterior, considero necesario constelar este principio de Fraser con el que se ha denominado el principio del humanismo. Entre sus defensores cabe citar a Martha Nussbaum quien apela a criterios relacionados con el ser

20 Vuelvo a recordar la formulación del principio: «Una cuestión está justamente enmarcada si y sólo si todos y cada uno de los sometidos a la(s) estructura(s) de gobernación que regula(n) las áreas relevantes de la interacción social reciben igual consideración».

21 Recuérdese que otro principio normativo que da respuesta al quién de la justicia es el denominado principio de la condición de ser miembro. Propondría una solución apelando a criterios de pertenencia política tales como la ciudadanía. Fraser también lo examinará y mostrará sus insuficiencias. La más importante carencia, como señala la autora, será que el principio conduce a ratificar los nacionalismo excluyentes de los poderosos.

22 Fraser considera que este nuevo principio que propone supera también las limitaciones del principio de todos los afectados: son sujetos de justicia aquellos co-imbricados en una red de relaciones causales. Ella misma asumía en obras anteriores este principio. Uno de los problemas que ve en él es que cae víctima de la reductio ad absurdum del efecto mariposa: todo está relacionado con todo. 
humano, tales como la autonomía o la racionalidad, para responder al quién de la justicia ${ }^{23}$. El punto más débil de este principio, para Fraser, es su elevado nivel de abstracción.

Desde mi punto de vista esta no es la única definición que podemos dar del principio del humanismo. Intentaré reformular el principio para, posteriormente, mostrar su pertinente constelación con el principio de todos los sujetos. Para su reformulación recontextualizaré el humanismo presente en uno de los pensamientos más singulares del siglo XIX, me refiero a la obra de Sören Kierkegaard. Estoy empleando el verbo «recontextualizar» en el mismo sentido en que lo usó Foucault, en su momento, y la misma Nancy Fraser. A saber, no voy a permanecer fiel a Kierkegaard sino que lo historizo, se trata de una recontextualización de determinados textos o tópicos bajo el prisma de unas categorías que, en su momento, no estaban al alcance del autor en cuestión. La recontextualización o historización de un pensamiento es algo común en la hermenéutica filosófica. A pesar del alejamiento temporal entre autores y de los intereses dispares que encontramos entre ellos, la riqueza de los pensamientos de filósofos clásicos, como por ejemplo el de Sören Kierkegaard, nos permite entresacar contenido normativo y recontextulizarlo. De este modo, en el siguiente apartado releeré al pensador danés, relacionando su humanismo con una posible definición actual del principio del humanismo.

\section{Releyendo a Kierkegaard desde el principio del humanismo}

El pensador danés es uno de los filósofos más arduos de interpretar. No elaboró un pensamiento académico sin más, sino que como él mismo afirmó, construyó un pensamiento con alcance religioso. El llamado Sócrates del Norte se presenta como escritor religioso ${ }^{24}$. Este aspecto ha conducido, en numerosas ocasiones, a pasar por alto el valor y la proyección filosófica de su obra que abarca, por citar tan sólo dos ejemplos, el pensamiento de Heidegger y el de Sartre. A esta característica peculiar hay que añadirle su forma tan poco ortodoxa, desde el punto de vista de la academia, de escribir. Se presenta como un antihegeliano que lucha contra la construcción de sistemas filosóficos, y tal actitud se traduce en un uso del lenguaje tildado por muchos de literario y poco académico. Su prosa irónica es un reflejo de un pensamiento que quiere mostrar las paradojas y contradicciones de cualquier existente que no vive en un Sistema, en una algoritmia conceptual que pretenda explicar el mundo ${ }^{25}$. A todas estas complejidades se le añade una nota más, la utilización que realiza el pensador danés de la seudonimia. Kierkegaard fue un autor muy prolífico y, como rasgo curioso, cabe destacar que de todas sus obras (más de cincuenta) tan sólo tres o cuatro son firmadas por él. El resto de obras son firmadas por seudónimos que en realidad se convierten en heterónimos. La razón de esta conversión nos la da el mismo Kierkegaard en una de las

23 Véase Nussbaum, M., «Patriotismo y cosmopolitismo» y «Réplica», en: M. Nussbaum (ed.): Los límites del patriotismo, Barcelona, Paidós, 1999, pp. 13-29 y pp. 159-173.

24 Véase Kierkegaard, S., Mi punto de vista como escritor religioso, Buenos Aires, Aguilar, 1959.

25 Como ejemplo de su ataque al Sistema, Kierkegaard nos dice: «Con la mayoría de los filósofos sistemáticos y sus sistemas ocurre lo mismo que con aquel que luego de construir para sí un castillo, habita en un pajar. Ellos no viven dentro de sus enormes edificios sistemáticos. En el campo del espíritu esto constituye una objeción capital. Las ideas de un hombre deben de ser su propia morada; de lo contrario, peor para ellas», en: S. Kierkegaard: Diario íntimo, Buenos Aires, Santiago Rueda, 1955, p. 147. 
pocas obras firmadas por él, Mi punto de vista como escritor religioso, en la que insiste en la necesidad de mencionar el nombre del seudónimo cuando se cite un pasaje de su obra: el pensador danés no identifica su pensamiento con el de sus heterónimos ${ }^{26}$. Dentro de la hermenéutica filosófica, tuvieron que pasar bastantes años para que se tomara en serio, en las obras del llamado Sócrates del Norte, el valor y el papel de la seudonimia.

Por tanto, la interpretación que realizaré tendrá en cuenta todas estas características propias de la obra de Kierkegaard. El humanismo kierkegaardiano que entresaco de sus obras se atiene, para ser fiel a los deseos del propio autor, a lo que Kierkegaard defendió en el más trascendental escrito firmado por él, Las obras del amor ${ }^{27}$. De igual modo, siguiendo con sus explicaciones, también tendré en cuenta alguna de las afirmaciones del único heterónimo que Kierkegaard situaba en una idealidad más alta a la suya, me refiero a Anti-Climacus, el cristiano extraordinario ${ }^{28}$.

Como antihegeliano luchó contra el sistema pero esta no sería su única lucha. La que más me interesa destacar tiene que ver con la reivindicación de la existencia frente a la esencia. El centro de la filosofía kierkegaardiana no se puebla con un número de esencias, el centro lo ocupa el existente, el sí mismo encarnado en el sujeto de carne y hueso. Este sujeto lleno de contradicciones y paradojas es la principal preocupación del pensador danés. Su teoría de la individuación dará una respuesta a una de las cuestiones más complejas para el pensador existencial: cómo podemos llegar a ser auténticos sí mismos.

En primer lugar, para poder dar el salto y alcanzar la autenticidad como individuos hemos de querer llegar a ser un sí mismo. Mostramos esta voluntad al reconocer nuestra vulnerabilidad cargada de contradicciones y paradojas ${ }^{29}$. Y precisamente, como nos enseña en Las obras del amor, sólo podremos superar nuestras contradicciones asumiendo nuestra dependencia hacia el otro ${ }^{30}$. Se trata de un triple reconocimiento: reconocemos nuestra vulnerabilidad, reconocemos la vulnerabilidad del otro y, por último, reconocemos que la única forma de superar esta vulnerabilidad es aceptando nuestra dependencia del otro. El sufrimiento y la angustia son dos manifestaciones de nuestra vulnerabilidad que han de ser superadas $^{31}$. Este paso sólo se conseguirá a través del otro y, más concretamente, a través el amor. El amor se convierte en el imperativo ético kierkegaardiano.

26 Véase Kierkegaard, S., Mi punto de vista como escritor religioso, op. cit., pp. 184-ss.

27 Kierkegaard, S., Las obras del amor, Salamanca, Ediciones Sígueme, 2006.

28 Así lo dice Kierkegaard: «Más tarde, sin embargo, apareció un nuevo pseudónimo, Anti-Climacus. Pero el hecho de que sea un pseudónimo (como el mismo nombre de Anti-Climacus indica) requiere que haya que considerarlo más bien como una señal de parada. Todos los pseudónimos anteriores están por bajo del 'autor edificante' [Kierkegaard se denomina de esta forma a sí mismo]; el nuevo pseudónimo representa una pseudonimidad más alta [...] la 'parada' se realiza señalando un ideal más alto», en: S. Kierkegaard: Mi punto de vista como escritor religioso, op. cit., p. 154.

29 En la explicación kierkegaardina el hombre del Sistema no duda de nada, lo tiene todo clarificado, clasificado y explicado en el Sistema.

30 Kierkegaard no utiliza el término otro, empleará el concepto de prójimo: «El prójimo es lo equitativo. El prójimo no es el amado por quien tienes predilección apasionada, ni tampoco es el amigo por quien tienes predilección apasionada. El prójimo tampoco es, en el caso de que tú mismo seas alguien cultivado, el cultivado, con el que te igualas por la cultura [...] El prójimo es cada ser humano», en: S. Kierkegaard: Las obras del amor, op. cit., pp. 84-85.

31 Véase Kierkegaard, S. (Anti-Climacus), La enfermedad mortal, Madrid, Guadarrama, 1969. Escribo intencionadamente el seudónimo entre paréntesis, por el significado que tiene a la hora de interpretar el pensamiento del filósofo danés. 
El principio del humanismo en Kierkegaard nos conduce a un sujeto de carne y hueso, no al humano general y abstracto. Este individuo concreto sufre como sujeto estético, ético, religioso o ético-religioso ${ }^{32}$. La idiosincrasia del humanismo kierkegaardiano reside en tres puntos centrales: por una parte, lo humano se personaliza en un sintiente concreto; por otra, la característica existencial de ese sujeto es su capacidad de sufrir; y por último, el sufrimiento y la angustia solo pueden ser superados a través del imperativo ético «Tú debes amar». La reconstrucción kierkegaardiana no solo supera el nivel de abstracción del principio del humanismo, sino que a diferencia de este último, subraya como rasgo distintivo del sujeto encarnado, la capacidad para sufrir, al mismo tiempo que exige como imperativo categórico, amar al otro. Digamos que la osadía kierkegardiana le conduce a tratar el amor como una cuestión de justicia.

Del pensamiento de Sören Kierkegaard bien se puede extraer un principio ético y moral que pueda responder al quién y al qué de la justicia transnacional. En primer lugar, resolveremos el quién de la justicia apelando a todo ser sintiente que sufre. En segundo lugar, para responder a lo que es un genuino asunto de justicia, el pensar kierkegaardiano exige una concepción sustantiva de la justicia, donde la erradicación del sufrimiento puede tener claramente dos planos, uno material, ligado a la redistribución y otro social y cultural ligado al reconocimiento del otro.

Evidentemente, como señalé con anterioridad, me he permitido una recontextualización del pensamiento de Kierkegaard para acabar afirmando la necesidad de algún nuevo principio, que sin abandonar las pretensiones del cosmopolitismo, lo supere. Este nuevo principio bien pudiera llamarse el principio de los seres sintientes. Es cierto que no puede responder a todas las problemáticas de la justicia internacional, y que deja al margen la dimensión de la representación y el cómo de la justicia entendido como la implementación institucional de las cuestiones de justicia.

A pesar de sus limitaciones considero que es necesario constelar este tipo de principio con el principio de todos los sujetos de Fraser. Explicaré las razones de la constelación propuesta.

\section{Tres argumentos a favor de la constelación de principios}

Las tres razones que mencioné, en un apartado anterior, para constelar el principio de todos los sujetos con alguna reformulación del principio del humanismo, denominado en mi propuesta como principio de los seres sintientes, están necesariamente vinculadas entre sí. Veamos el caso.

El primer argumento está relacionado con uno de los temas clásicos da la Filosofía Moral: la clasificación de las éticas en éticas que abordan las cuestiones morales, es decir,

32 Me estoy refiriendo a la distinción que realiza el pensador danés en su teoría de la individuación. Tradicionalmente se habla de tres estadios de existencia, el estadio estético, el ético y el religioso. Determinados heterónimos viven en estos estadios. En el primero estaría Johannes el Seductor, en el ético el Juez Wilhem y en el religioso aparece Anti- Climacus, el cristiano extraordinario. La mayoría de los intérpretes daneses y actuales hablan de un cuarto estadio, el ético-religioso. El religioso es de una idealidad tan alta que el auténtico sujeto ha de conformarse con vivir en este nuevo estadio. Kierkegaard reconoce su existencia en su Diario íntimo y en Las obras del amor. Precisamente en dos de las obras firmadas por él. 
las cuestiones de justicia y éticas ligadas a las cuestiones de la vida buena (cuestiones éticas o cuestiones de la vida no fallida). Metodológicamente la división es pertinente y más aún, si como kantianos estuviésemos buscando la fundamentación filosófica de la moral. Una cosa es dedicarse a las cuestiones de justicia y otra a las cuestiones de la vida buena.

Desde la interpretación que propongo, apelar sólo a lo procedimental y epistémico y olvidarse de lo sustantivo no es un buen compañero de viaje para una justicia internacional. Así lo he intentado mostrar en el artículo al revisar la obra de Rawls El derecho de gentes. Su planteamiento se aleja de una concepción sustantiva de la justicia, con todas las insuficiencias que ello acarrea. Para evitar, precisamente, tales carencias es por lo que considero más oportuno hablar de un continuo, y de una necesaria yuxtaposición, entre las cuestiones de justicia y las cuestiones de la vida buena. No se trata de no diferenciarlas, sino de buscar una constelación entre ambas. La solución a una modernidad descarrilada, que falla en un tema tan crucial como es el de la justicia internacional en general y el de la inmigración en particular, pasa por constelar las normas incondicionales y universales, los procedimientos y principios de un Estado de derecho, con los valores de una sociedad pluralista.

Es cierto que Fraser rechaza el mero valor epistémico de la justicia internacional y se introduce en el terreno de lo sustantivo, pero no es menos cierto, que este posicionamiento se vería reforzado si se vinculara su principio a algún otro más cercano al tradicional «humanismo», donde la vida buena del ser sintiente ocupa un lugar prioritario.

$\mathrm{Al}$ establecer la constelación de principios que propongo se consigue fortalecer el potencial motivacional que pudieran tener las cuestiones de justicia. Lo que enlaza con el segundo argumento a favor de la constelación: con la yuxtaposición de ambos principios, el principio de todos los sujetos y el principio de los seres sintientes, se implementa la carga motivacional del principio de Fraser. El sujeto sometido a una estructura de gobernación, que está regulando sus más importantes interacciones sociales, es un sujeto de carne y hueso que sufre la presión de un poder coercitivo. Al reconocer su vulnerabilidad y sufrimiento, lo reconocemos como igual y dependiente, hasta tal punto que podremos empáticamente exigir justicia y reclamar igual consideración para con él. Evidentemente, no se puede legislar sobre la solidaridad o la empatía, pero si podemos debatir, dentro de un modelo de democracia deliberativista, la necesidad de educar sobres estos valores y sentimientos ${ }^{33}$. Para que realmente esto sea posible, es necesario que a los principios más formales de justicia se les yuxtaponga, tanto en la esfera pública formal como informal, un principio con carga más sustantiva, que una al sujeto sometido a una estructura de gobernación con su sufrimiento real.

El último argumento a favor de la constelación de principios enlaza con la búsqueda de una mejor respuesta al qué de la justicia internacional. Si queremos que la respuesta al qué sea el reflejo de lo que Fraser denomina una ontología social multidimensional, a saber, tener en consideración los asuntos relacionados con la distribución fallida, el reconocimiento fallido y la representación fallida, es absolutamente pertinente dirigir la mirada hacia el sufrimiento real y encarnado en los seres sintientes, hacia su vulnerabilidad. En este sentido la mejor respuesta, a una ontología social de diferentes dimensiones, no viene de la mano de la aceptación de un solo principio normativo, sino de la constelación de dos principios como los que he expuesto.

33 Véase Putnam, H., y Habermas, J., Normas y valores, Madrid, Trotta, 2008. 
Es cierto que todo este entramado conceptual requiere para ser efectivo una vía institucional, una estructura democrática capaz de abrazar nuevas instituciones democráticas globales, pero esto ya es tema de otro artículo.

\section{Conclusión}

Después de la publicación en los años setenta de Teoría de la justicia de Rawls, el tema de la justicia en el ámbito de los estados nacionales sufrió un verdadero giro ilustrado. Se une el planteamiento rawlsiano al salto occidental a una Segunda Ilustración (término empleado por mí en otros escritos) ${ }^{34}$. La redistribución y el reconocimiento fueron elementos reivindicados por los movimientos sociales y de derechos civiles que recorrieron las calles occidentales desde los años sesenta. Estos dos conceptos se convertirán en una respuesta compacta al qué de la justicia.

En este artículo he pretendido mostrar como años más tarde estábamos esperando una respuesta igual de compacta para el ámbito internacional. La respuesta de Rawls llegó en 1999 y no cumplió las expectativas. Daba una respuesta menguante al qué y al quién de la justicia en el derecho internacional. En cuanto al qué su respuesta fue clara: la estabilidad y paz entre los pueblos liberales y decentes. El quién también quedó bien pergeñado: los pueblos que no los estados, ni mucho menos los individuos, serán los sujetos de la justicia.

Las críticas no se hicieron esperar. He querido remarcar una de las críticas y la propuesta, desde mi punto de vista, más correcta, coherente y global, me refiero, a la visión que presenta Nancy Fraser en Escalas de justicia. Un enfoque acorde y capaz de responder a los nuevos retos transnacionales y globales.

Por último, he dado diferentes razones para constelar el principio defendido por Fraser con una interpretación peculiar del principio del humanismo. En el fondo de esta propuesta se encuentra mi anhelo de dar una respuesta, tan justa como emocional, a temas tan importantes como la inmigración. En este tipo de conflictos es donde encontramos al auténtico sujeto vulnerable, de ahí, mi intento de implementar motivacionalmente el principio fraseriano.

Con la constelación de ambos principios propuestos -el principio de todos los sujetos de Fraser y el principio de los seres sintientes- pretendo esbozar la posibilidad de una Tercera Ilustración que atienda el sufrimiento que acarrea, la distribución fallida, el reconocimiento y la representación fallida, de todos aquellos que se encuentran «sometidos a una estructura de gobernación que regula las áreas relevantes de la interacción social».

\section{Referencias}

Adorno, T. W. (1987), Minima moralia, Madrid, Taurus.

Adorno, T. W. (1992), Dialéctica negativa, Madrid, Taurus.

Adorno, T. W. y Horkheimer, M. (1994), Dialéctica de la Ilustración, Madrid, Trotta.

Applebaum, A. (2012), Historia de los campos de concentración soviéticos, Barcelona, Penguin Random House.

Arendt, H. (1998), Los orígenes del totalitarismo, Madrid, Taurus.

34 Véase Herrera Guevara, A., Ilustrados o bárbaros, Madrid, Plaza y Valdés, 2014. 
Buchanan, A. (2006), «Taking the Human out of Human Rights», en: R. Martin and D. A. Reidy (eds.): Rawls's Law of Peoples. A realistic utopia?, Blackwell Publishing.

Fraser, N. (2008), Escalas de justicia, Barcelona, Herder.

Habermas, J. (1999), La inclusión del otro, Barcelona, Paidós.

Herrera Guevara, A. (2014), Ilustrados o bárbaros, Madrid, Plaza y Valdés.

Kierkegaard, S. (1955), Diario íntimo, Buenos Aires, Santiago Rueda.

Kierkegaard, S. (1959), Mi punto de vista como escritor religioso, Buenos Aires, Aguilar.

Kierkegaard, S. (1969), La enfermedad mortal, Madrid, Guadarrama.

Kierkegaard, S. (2006), Las obras del amor, Salamanca, Ediciones Sígueme.

Miller, D. (2005), «Immigration: The Case for Limits», en A. I. Cohen and C. H. Wellman (eds.): Contemporary Debates in Applied Ethics, Oxford, Blackwell Publishing.

Nussbaum, M. (1999), «Patriotismo y cosmopolitismo» y «Réplica», en: M. Nussbaum (ed.): Los límites del patriotismo, Barcelona, Paidós.

Pettit, P. (1999), Republicanismo, Barcelona, Paidós.

Putnam, H. y Habermas, J. (2008), Normas y valores, Madrid, Trotta.

Rawls, J. (1979), Teoría de la justicia, México, FCE.

Rawls, J. (2001), El derecho de gentes, Barcelona, Paidós. 
